Spring, Hannah ORCID:

https://orcid.org/0000-0001-9836-2795, Howlett, Fiona ORCID: https://orcid.org/0000-0002-9957-1908, Connor, Claire, Alderson, Ashton, Antcliff, Joe, Dutton, Kimberley, Gray, Oliva, Hirst, Emily, Jabeen, Zeba, Jamil, Myra, Mattimoe, Sally and Waister, Siobhan (2018) The value and meaning of a community drop-in service for asylum seekers and refugees. International Journal of Migration, Health and Social Care, 15 (1). pp. 31-45.

Downloaded from: http://ray.yorksj.ac.uk/id/eprint/3542/

The version presented here may differ from the published version or version of record. If you intend to cite from the work you are advised to consult the publisher's version: https://www.emeraldinsight.com/doi/full/10.1108/IJMHSC-07-2018-0042

Research at York St John (RaY) is an institutional repository. It supports the principles of open access by making the research outputs of the University available in digital form. Copyright of the items stored in RaY reside with the authors and/or other copyright owners. Users may access full text items free of charge, and may download a copy for private study or non-commercial research. For further reuse terms, see licence terms governing individual outputs. Institutional Repository Policy Statement

\title{
RaY
}

Research at the University of York St John

For more information please contact RaY at ray@yorksj.ac.uk 
emerald International Journal of Migration, Health and Social Care
PUBLISHING

\section{The value and meaning of a community drop-in service for asylum seekers and refugees}

\begin{tabular}{|r|l|}
\hline Journal: & International Journal of Migration, Health and Social Care \\
\hline Manuscript ID & IJMHSC-07-2018-0042.R1 \\
\hline Manuscript Type: & Academic Paper \\
\hline Keywords: & $\begin{array}{l}\text { Asylum Seekers, Refugees, Community Services, Occupation, Meaning, } \\
\text { Cultural Relevance }\end{array}$ \\
\hline \multicolumn{2}{|c}{} \\
\hline
\end{tabular}

SCHOLARONE ${ }^{\text {"w }}$

Manuscripts 


\section{Introduction}

Decades of sustained war and political unrest have caused unprecedented global civilian displacement. The result of this is a significant negative impact on health and wellbeing, and a lack of access to dignified and meaningful occupation among refugees and asylum seekers (World Federation of Occupational Therapists, 2014). Occupations are "the everyday activities that people do as individuals, in families and with communities to occupy time and bring meaning and purpose to life. Occupations include things people need to, want to and are expected to do" (World Federation of Occupational Therapists, 2016). Participating in meaningful occupation is a fundamental aspect of the human experience (Hassekus, 2011., Wilcock, 2006) and a significant indicator of health and well-being Gallagher et al, 2015). Furthermore, it is identified as a key human right and a matter of occupational justice (Hammell, 2017; Whiteford, 2005; World Federation of Occupational Therapists, 2006).

Studies have shown that occupational engagement and having choice in occupations can have a positive impact on the health and well-being of refugees (Suleman and Whiteford, 2013; Wilcock, 2006; Bishop and Purcell, 2013). Research suggests that occupational disruption and deprivation are however widespread among this population (Morville, 2014; Suleman and Whiteford, 2013). Every person 'belongs' in a familial and societal context and each individual has different values and traditions which means that occupations are perceived differently (Iwama, 2013). When a person becomes forcibly displaced from that familial and societal context due to war and political unrest, this can result in significant consequences for occupational engagement and wellbeing. 


\section{Migration and impact on occupation}

Those seeking asylum or refugee status in the United Kingdom encounter substantial barriers to occupational participation and community integration and all aspects of the person can be affected (Durocher, 2014; Huot et al, 2016). Conflict and contradiction are rife in the laws affecting those seeking asylum, creating occupational apartheid (Davies, 2009; Pollard and Sakellariou, 2017; Wilson, 2009). Examples include the prohibition to work, lack of clarity on status and access to healthcare, and the tension between detention laws, human rights legislation and freedom of movement (British Institute of Human Rights, 2017; Reeves et al, 2006; United Nations General Assembly, 1951). This is frequently exacerbated by the fact that asylum seekers are often processing multiple human and material losses suffered prior to or during their journey to a host country (Douglas, 2010). Integration and occupational adaptation are therefore difficult to achieve without support (Werge-Olsen and Vik, 2012). Furthermore, the nature of occupations available is of key importance to health and wellbeing. Smith (2015) found that altruistic occupations held the greatest meaning for asylum seekers and created the strongest sense of belonging, attributing this to the values and priorities associated with collectivist cultures. This is in stark contrast to the predominance of individualistic ideals and cultures more commonly associated with Western societies such as that of the UK. This is a further contributing factor to the challenges of resettlement and occupation. These challenges can ultimately limit the ability and volition of individuals to integrate successfully into society (Smith, 2015). 


\section{Rationale}

In June 2018 the United Nations Refugee Agency recorded 68.5 million forcibly displaced people worldwide (2018), with $85 \%$ being hosted in developing countries. In the same year, 42,352 asylum seekers had pending refugee status in the United Kingdom with the greatest dispersal currently being in the North West of England (Refugee Council, 2018). Unlike initiatives such as the one-stop-shop in other European countries, the UK does not have a co-ordinated approach to support the integration of migrants into the community (Dali, 2014; Oliveria, C, 2009). Services are often fragmented and poorly resourced. Given that the international political climate remains unstable, there is likely to be a continuation of people entering the UK seeking asylum and a resulting demand for support services to effectively meet the needs of this diverse group. At the time of writing there are no studies exploring local responses to the needs of this client group. However, in the UK commentary and discussion has identified that asylum seekers and refugees particularly value occupationally-focused opportunities alongside practical and emotional support from services that help them negotiate the complex and unfamiliar processes of resettlement and orientation (Smith, 2015). The study reported in this paper centred on a charitable drop-in centre for asylum seekers and refugees based in the NorthEast of England. The drop-in centre provides services similar to those identified by Smith (2015) and Oliveria (2009) as being valuable, and anecdotal reports from the service users seemed to echo these observations.

There is scope to develop a body of UK focussed research evidence to consider the value and meaning of existing support services to the asylum seekers and refugees who are using them. There have been calls in the literature for research focussing 
on occupational contexts of the lived experience of this group and how this might inform policy and practice development (Bennett et al, 2012). Insights into occupational preferences that such services could support may inform future service development at local and national levels and, more widely, highlight potential opportunities for health and social care services provision among this growing population (Howlett and Spring, 2018).

\section{Service Profile}

The drop-in service based in the North-East of England operates twice weekly for two hours and was established ten years ago. Following applicant processing, people seeking asylum in the UK are transferred from one of sixteen detention centres to a number of specific localities. It is one of these areas that the drop-in centre is located and the service was set up in response to local need. It is operated by a range of volunteers with variety of professional and non-professional backgrounds. The service receives $£ 100$ of charitable funding per month plus free use of the community hall from the local Parish church. The service also receives occasional ad-hoc donations from other sources in the wider community. The service aims to provide basic unmet needs such as food, clothing and household items and relies heavily on donations. Practical advice and support on the processes of applying for asylum, and accessing healthcare and other external social support agencies is offered alongside English classes from professional volunteers. Attendance at the service has a significant diversity of cultures and ethnicities and is regularly attended by over 180 members (male and female) from over 20 different countries, predominantly Africa, the Middle East and Eastern 
Europe. With continued and increasing international political instability the service has expanded and numbers attending the service have risen considerably in recent years. Funding to the service has not risen in line with this increased demand and this places significant limitations and constraints on the scope of services that can be delivered. Increasing demand has enabled increased opportunities for those who use the service to play active roles in helping to run it, and over time the centre has become one that is run by refugees and asylum seekers for refugees and asylum seekers in collaboration with the British volunteering team. The service provides a safe social space and the opportunity to undertake productive voluntary roles, which promotes occupational wellbeing.

\section{Study Aim}

This study aimed to explore the value and meaning of a drop-in centre service offering social and occupational support for refugees and asylum seekers and to identify the occupational preferences of the service users.

\section{Methods}

The study applied a phenomenological approach within the interpretivist paradigm. Interpretative phenomenology is an established choice for cross-cultural qualitative research (Liamputtong, 2010; Usher and Jackson, 2014) and has particular salience when applied in research with refugees (Schweitzer and Steel, 2008). The application of hermeneutics within this approach enables the exploration of personal meaning and experience relating to a specific phenomenon and allows ambiguity 
and complexity to co-exist within the findings (Finlay, 2011; Smith et al, 2009). Furthermore, it allows for openness to human experience which may be outside of the experience of the researcher and seeks to understand phenomena that may not initially be self-evident. A priori assumptions of the researchers can be set aside allowing space for the indigenous knowledge and experiences of the participants to be privileged (Schweitzer and Steel, 2008). This was essential due to the nature of the study, the difference in cultural backgrounds of the researchers and participants, and the potential diversity of opinions and experience. It is also congruent with the study aim and of capturing personal experience (Birks, 2014).

\section{Recruitment}

Recruitment to the study had two strands - rapport building followed by gatekeeper screening of volunteering participants. In qualitative research, gatekeepers are commonly used as a means of ethically and efficiently screening potential participants for suitability (Ryen, 2008). The gatekeeper in this study was the chairperson of the drop-in centre, a well-respected and trusted representative of the service users. The establishment of trust and good relationships in cross-cultural research is crucial and is particularly important when working with marginalised groups such as refugees and indigenous populations who are likely to have experienced significant abuses of trust (Schweitzer and Steel, 2008., Barata et al, 2006). The collection of high quality data from participant groups from different cultures requires good rapport, and for the researchers, cultural sensitivity and a willingness to learn (Eide and Allen, 2005; Erden, 2017). This should be developed before interviews take place and should be ongoing throughout the life of the 
research (Liamputtong, 2008). Participation in appropriate training for the researchers is therefore necessary (Laverack and Brown, 2003). Prior to commencement of the study, cultural awareness preparation was addressed through various processes. This included an introduction to the drop-in centre and discussion of issues relevant to people seeking asylum and refugee status in the UK. This was presented to the research team by the gatekeeper and three drop-in centre service users who were seeking asylum in the UK. In addition, the research team received separate cultural awareness training. Prior to the commencement of any recruitment or data collection activities, the research team also visited the centre to engage in social activities and discuss the research project informally. This helped develop rapport and build trust with service users. On the day of the visit and before the service users began arriving at the drop-in centre, the researchers received further briefing by the gatekeeper on appropriate levels of interaction and boundaries that should be observed.

\section{Sample}

Given that cross-cultural research of this nature should be carried out in collaboration with individual/s who are working closely with and have established relationships with the group (Eide and Allen, 2005; Laverack and Brown, 2003; Sixsmith, Boneham and Goldring, 2003), a purposive approach to recruitment was guided by the gatekeeper. This was judged the best way of ensuring a range of age, gender, origin and asylum status within the sample. 
Participants over the age of 18 and who regularly attended the service were eligible to participate in the study. We excluded people who were emotionally fragile or experiencing acute mental health issues. Guidance from the gatekeeper enabled reliable screening of potential participants for ethical contraindications such as these. An eagerness amongst the service users to contribute, perhaps as a consequence of initial rapport building and information giving activities, led to the recruitment of 18 participants (11 men, 7 women). An overview of participants is provided in Table 1.

\section{Ethics}

Ethics approval was obtained from the researcher's institutional ethics committee. It has been highlighted that potential participants in intercultural research are more likely to display a keenness to be involved if they have fully understood the research and can see that it poses no risk or threat to them. Interpretation and verbal explanation is often key to this process Barata, 2006). Informed consent was obtained in partnership with the gatekeeper and where possible, prior to the interviewers arriving at the drop-in centre. Service users expressing an interest in the study were given an information sheet explaining the project and this was accompanied by verbal explanations by the Gatekeeper and the use of interpreters where necessary. Participants were given assistance to read and sign consent forms, and informed of the cut-off date for verbal or written withdrawal from the project. 


\title{
Data Collection
}

The research team comprised 12 researchers. Studies have suggested that research participants provide the most accurate accounts to researchers who have similar cultural backgrounds (Adamson and Donovan, 2002; Crawford and Turpin, 2018; Richardson, 2017). The drop-in centre is home to refugees and asylum seekers from over 20 different countries representing broad cultural diversity, therefore it was not possible have full cultural representation within the research team. The research team did however have two bi-cultural members who had insight and experience of collectivist culture, this being the predominant culture of those attending the drop-in centre. Data gathering was aided considerably by this.

\begin{abstract}
As a recognised data gathering technique in qualitative research semi-structured interviewing was used (Cresswell, 2014). Focus groups were eliminated because differing proficiency levels in English and cultural differences had the potential to affect group dynamics and pose significant challenges to effective communication. Interviews took place over four weeks at the drop-in centre.
\end{abstract}

The drop-in centre is very much 'owned' by those that use it and it is a familiar environment that provides a communal meeting space. On each visit the interviewers were welcomed as valued guests at the drop-in centre. Researchers sought to generate an atmosphere of collaboration and mutual exchange, distancing the interview environment from participants' previous interview experiences, which could evoke difficult feelings. The interviews were conducted as a four person conversation with two researchers and two participants on each occasion. This 
created an informal, relaxed interview atmosphere. Schweitzer and Steel (2008) identify the importance of relationship to participants in cross-cultural research and that the 'research interview' can often be accompanied by hospitality. We recognised that hospitality was of strong cultural importance at the drop-in centre; homemade cakes and hot drinks were therefore taken to share during interviews as a meaningful gesture and this was well received.

Due to the range and diversity of service users, the full range of languages spoken by them was not reflected in the sample. Two members of the research team were bilingual and interviews were conducted in English, Urdu or Punjabi. Where interviews were not conducted in English, interview transcription was completed by the bi-lingual members of the research team who conducted the interviews. Where literal translation of some words or phrases was not possible due to the peculiarities of different languages, these were verbally explained during each research team debrief. This is in line with the layering aspect of the interpretative phenomenological analysis methodology.

The study did not directly address sensitive or traumatic past experiences but focussed positively on the present. Interview questions were adapted from Bishop and Purcell's (2013) qualitative study of a similar population group (see Table 2) and utilised probing questions for the elicitation of further rich data. Interviews were led by the contributions of the participants and lasted between 5 and 20 minutes. The interviews were audio recorded with consent for later transcription. Each pair of interviewers transcribed their interviews verbatim. All transcriptions and audio 
recordings were then circulated among the team. Participants were offered the transcriptions of their interviews and were made aware through the consent process that the audio recordings would be destroyed after transcription.

\section{Data Analysis}

Interpretive phenomenological analysis was used, applying individual line-by-line analysis for emergent patterns, developed and checked through reflection, group dialogue, collaboration, audit and supervision (Smith et al, 2009). Each interview pair analysed their own verbatim transcriptions and those of the next pair in the data collection process for the purposes of member checking. After each set of interviews the whole team came together for debrief during which interpretations of the transcriptions were scrutinised through discussion. The debrief provided additional context from those that had conducted the interviews and which, for the other team members, could not have been derived from simply listening to the interview transcripts alone. This discussion helped to illuminate small nuances and other meaning that would otherwise have been hidden to members of the research team who had not been present at the interviews. Broader reflection of the interview transcripts in this manner by the whole team aided deeper interpretation of the data and allowed coding and themes to be developed and unanimously agreed through group discussion.

Interview skills were explored by the research team in advance to ensure best practice (Finlay, 2006). The research team were mindful of gender and cultural differences between the research team and the participants. Studies have 
highlighted the dangers of using Western approaches to data collection and analysis in non-western participant groups (Baird et al, 2017) and the researchers were conscious of their own training in opposition to the cultural perspectives of participants (Iwama, 2010; Liamputtong, 2010). Researcher presence within the study was recognised and personal assumptions mitigated through the team meetings and discussion of the socio-political context (Usher and Jackson, 2014). These discussions were also positively supported by the bi-cultural members of the research team. Written and audio records of team meetings were created for individual reflection.

For rigour, three pilot interviews were conducted by one interview pair, followed by a team discussion to identify any flaws in the interview schedule and procedure. The team's size and presence of bi-cultural members enabled strong triangulation, strong analysis and reduced individual bias (Finlay, 2011; Cresswell, 2014). Participants were offered a written summary of their interview transcript for respondent validation. Researchers' language skills reduced the risk of weakened data interpretation caused by third party translators (Green and Thorogood, 2014).

\section{Findings}

Analysis of the data identified four closely connected themes which were used to articulate the most prevalent areas of meaning for service users. These were the need to experience a sense of community, being able to make an altruistic contribution within the local and drop-in centre community, the need for societal 
integration, and having the opportunity to engage in meaningful and productive occupational preferences. Sense of community and altruistic contributions as themes were deeply interconnected, as were the themes of societal integration and occupational preference making them difficult to present as separate entities. The two combined themes of sense of community and altruism, and integration and occupational preferences are presented below.

\section{Sense of Community and Altruism}

Feeling a sense of community was the strongest theme, with 17 out of 18 participants expressing community as an important element of the drop-in centre's personal value. These feelings were expressed mainly within the contexts of the more localised community of asylum seekers, refugees and service volunteers and linked closely with ideals of collectivist culture. While articulated differently, the desire to feel part of something, to belong, was the overriding sense from all participants.

"Makes you feel like you belong to something, you know you come here, you see many people, people you can interact with, talk with and feel welcomed in the community." (F8)

"It, it helps to come here, to make friends and they're wonderful people around [...] For me it's about, yeah making friends." (F1) 
Altruism was closely linked to the theme of community with 10 participants making specific reference to using the drop-in centre as an opportunity for altruistic activities, such as interpreting for new arrivals.

"People from other countries, can't speak English proper, I can interpret. [...] I can help them yeah, but not very, I'm not saying very good, but I can help them as much as I can." (M2)

Interwoven within this altruistic theme was gratitude for receiving help, an implied sense of repaying a debt to English volunteers by supporting the work of the drop-in centre in whatever way possible.

"They've done a lot for me, so in my own little way I can contribute and come and help them. I like to do that, yeah." (F1)

This theme suggests that empathy was strong among service users, both towards one another and to the English volunteers running the service. While participants were sincere in their gratitude for shelter and asylum in Britain, there was a clear sense that the drop-in centre met a cultural need for community among the service users which was not being fulfilled in the wider community. There are several reasons for this; firstly the impetus to integrate into British society was strong but the asylum process closed off many of the usual mechanisms for 'plugging in' to a new environment (Davies, 2009; Lunden, 2012). Aligning with Mirza's (2012) findings on 
disabled refugee experiences, inability to work and lack of money were evidently barriers to professional and social community integration. Many participants focussed on what was positive about their situation but others spoke more frankly about these challenges.

"The vast majority of them is er, with the economy, they got a problem with money, you know and that's the main problem they got [...] yeah, they need more support of this." (M2)

Secondly, alongside restricted integration strategies it was clear that cultural experience also played a role in the value of the drop-in centre. Gupta \& Sullivan (2013) found that western social and community interactions were scarcer and more superficial than in other cultures due to time pressures, a point which also emerged in this study. One participant expressed surprise at the lack of day to day community interaction in this country compared with the Middle East:

"Everybody like friendly, doesn't stay in the house, always together outside, to playing, to the coffee shop, to watch football or playing cards [...] first time I come to here I am feeling very sad and er...boring, [ ...] here in England nobody come to visit you or to see you..." (M6)

The importance of community was deeply felt and all participants expressed feelings of happiness at seeing people and spending time together at the drop-in centre. The 
cultural similarities between participants of different nationalities was notable. Together with a shared experience of forced migration, this underlying factor of collectivism served as a bonding element at the drop-in centre.

In addition, some participants who had achieved a high degree of integration (for example, obtaining refugee status and accessing mainstream further education or employment) continued to attend the drop-in centre regularly.

"I'd feel guilty if I didn't come down. I'd feel I'm missing something, [...] I work in [location] and I'm, I'm, every time I'm bound to how can I skip it on a Thursday or Tuesday at least to come in and meet..." (M9)

Two points arise from this; first, the desire for an enduring 'live' connection with one's primary culture, as found by Heigl et al (2011), who emphasise the distinction between integration and assimilation, and Gupta \& Sullivan (2013), who found that female immigrants sought an active balance between the two. Second, the expression of an altruistic desire to help others on their asylum journeys.

There are strong parallels with Smith's (2015) findings linking altruism as an expectation consistent with a collectivist cultural background. Examples of altruistic behaviour were articulated as a natural, expected way of being: 
"In my country, er, my family just they want to help people, just are interested in to help people. [...] Doesn't matter where he come from, what look like, what his background." (M3)

It was also notable that altruism was motivated at times by a variety of religious beliefs as well as cultural norms. "We work in our Gudwara voluntarily, we can work here as well." (M11)

Equally the study findings support Smith's (2015) assertion that altruistic engagement plays a part in maintaining wellbeing. This was most evident in participants with refugee status, whose greater sense of security perhaps afforded a more outward-looking focus than those lately arrived whose focus tended more towards immediate personal needs and priorities. One participant described that transition with great self-awareness.

"Mmm, when I came in beginning I came just to see, learn English, meet people or if I need any help, all those things. But I felt in that time, if they need any help from me, I can help them with something." (F4)

These findings suggest that the occupational needs and motivations of this population group cannot be understood without knowledge of the differences between collectivist and individualist (Western) cultures. 


\section{Occupational Preferences and Societal Integration}

Institutional factors govern the range of occupations open to refugees and create many barriers to both integration and occupational participation (Gupta and Sullivan, 2013). However, this study's findings uncovered great resourcefulness and a desire to make the most of the occupational opportunities available (Davies, 2009); for example, in the obvious absence of paid work opportunities, a strong productive drive remained evident in occupational preferences, such as practical crafts and skills development. Service users took pride in these skills and were conscious of the demand for more of these opportunities in the drop-in centre. Two thirds of the participants felt that the drop-in centre provided meaningful occupation in various forms. One participant had been a professional hairdresser and now used his skills (unpaid) at the drop-in centre.

"I am coming here [...] I say em... like cut hair...volunteer in here. I am two years working in this drop in." (M16)

Several participants described the drop-in centre as a focal point and a reason to go out. Unable to work and with little money, there was a clearly expressed need to fill time and to build structure and routine into their daily lives.

"So that gives me a time, you know, a routine in my daily life, you know to come here, to help. Yeah to have a routine in life because you can kind of get bored when just staying at home" (F1) 
Leisure and skills activities offered at the drop-in centre were particularly meaningful and a priority to many participants, both as a way of experiencing community integration and as a means of passing the time, since financial constraints make leisure activities and socialising in the wider community largely inaccessible. In particular, pool, table tennis, English classes and the opportunity to learn how to use a sewing machine were identified, the latter being equally valued by both genders.

"To bring like something to do, like er, machine or, to give people to do something. Like feeling better when you do something and you happy, you do well." (M6)

Games were dominated and valued more by male service users, "The table tennis [...] it's a very serious game here." (F1). Socialising was also articulated as a coping strategy to distract from worries and concerns.

"When somebody's you know, when they are boring or stressed you know on the street, I said why do you waste your time, come to here have a cup of tea, enjoy, make some friends." (M15)

Men talked more positively about occupational opportunities provided by the drop-in centre than the women, and both male and female participants expressed the need for development of specific women's and children's activities. Knitting and crocheting had previously been well received but space restrictions, availability of childcare and 
funding impeded further development of groups and therefore negatively affected the engagement of mothers in activities.

"People from outside coming to encourage women to participate and do something at least, not just come and just sit have cup of coffee, maybe that will be helpful" (F18)

While both genders accessed craft opportunities, only men used the pool, table football and table tennis facilities. This could be cultural propriety; a woman might hesitate to join an all-male group, for example, or the games may be viewed as male pursuits. Similarly, it was noted during visits to the drop-in centre that the English language classes were predominantly attended by men, which may dissuade women from joining the groups, effectively blocking their acquisition of the host language, which is key to societal integration (Gupta and Sullivan, 2013). The legal restrictions on asylum seekers prevent immersive routes to learning English such as taking a part-time job or entering the education system. Arguably, they may therefore be the most at risk of long term isolation through remaining dislocated from the host culture and society. One participant explained that the mixed gender space at the drop-in centre dissuaded some women from attending for reasons of safety.

"If they get some funds maybe the women get involved more, because the women, they don't come very often because they think men are here and the troubles are there, you know..." (F4) 
Dedicated activities for women in separate areas of the drop-in centre were therefore perceived as important. This is likely to be a fundamental aspect in improving the support for female asylum seekers and refugees to integrate successfully into the wider community.

Steindl et al (2008) found that asylum seekers were accustomed to relying on relatives for pragmatic and emotional support and developed new social relationships to fill this vacuum. In contrast to this, although participants in this study expressed a strong sense of goodwill and commitment towards other drop-in centre users, the use of shared childcare to free women to engage in other occupations was not yet in evidence at the drop-in centre, perhaps due to a heightened sense of caution as a result of the journey to claim asylum.

"I kind of just, have to be careful, because I am a bit careful, because if anything happens, you know, if any argument or something, because I don't want [Daughter] to be there...l have to keep her with me." (F1)

"The kids need to have, you know, some, er, place or area for playing." (F14)

Occupations focussed on broader societal integration stood out as meaningful, with acquisition of language frequently mentioned. Several participants referred to the drop-in centre's role in supporting their integration into British culture and society. 
The drive to learn or improve English was strong, accompanied by an awareness that British culture was different and the importance of understanding social conventions.

"I come here so that I can come and understand the world and come to learn some English and how to talk to people." (M12).

"We can get familiar with other ideas, other opinion and if we are making mistake they can tell us the, you know [...] they can for example tell us and correct us." (F14)

Linking with the strong need to connect with community, understanding other cultures around them was also articulated by some of the participants.

"I get to know what Pakistanis, I get to know what er, Kurdistan is like and I get to know everyone else [...] as far as erm Sri Lanka or something like that." (M9).

This may not be typical in support services with a narrower ethnic mix but cultural and ethnic diversity was a strong feature of this drop-in centre service. A third of participants found the drop-in centre important for transition. This was expressed both in immediate terms and with reference to longer term integration into society. 
"First, they know other people and they can improve English, if they want, or... when they get their status somebody can help them, often in the future to find, like, job or to be connected with others [...] to make new networks, not just stay..." (F4)

In particular, the hope for future employment is noteworthy, suggesting the drop-in centre's perceived value as a stepping-stone to future volunteering opportunities, productivity and the possibility of making an economic contribution.

Practical assistance and support was important to all participants, though this was more marked among newer arrivals whose right to remain depended on making a successful claim through complex administrative channels. Understandably in these cases, an element of occupational imbalance was evident because basic necessities and achieving security ("At times we get things free" (F8) overrode all other occupational engagement, "They advise you on the way how to handle a few things in the asylum seeker process" (F18). However, practical help appeared to remain of value across all stages of the asylum process.

"I've got a new flat and got plenty of stuff from here. [...] I haven't got enough money to spend for the kitchen stuff and for example more clothing" (M7)

"People bring things for children like nappies [...] there aren't other drop-in centres where you could get that kind of help, you know." (F1) 
The drop-in centre also allowed service users to become 'official' volunteers and undertake specific roles, such as hospitality or managing the signing in register. These were taken very seriously by service users and seen almost as an alternative kind of employment, positions of trust and respect, even among volunteers who had held high-ranking or skilled jobs in their home countries. While Heigl et al (2011) found that adopting roles for which people were underqualified engendered negative feeling, here this appeared to be outweighed by the altruistic element of the roles. This shows positive evidence of occupational deprivation being mitigated by successful occupational adaptation and occupational change (Huot, 2016) which in turns plays a role in supporting wider community and societal integration.

\section{Findings Summary}

The influence of collectivist culture on participants' attitudes, behaviour and choices cannot be overlooked. All occupational choices were framed in a group context, even potentially solitary pursuits such as the crafts. Personal agency in Eastern culture is vastly different from the West because there is no concept of self in an individualist sense; self-perception comes through reference to the social and physical context and is always interpreted as part of a greater, interdependent whole (Iwama, 2010). For someone with this background, community is a mirror in which one sees, situates and understands oneself. Heigl et al (2011) found that most occupations in a collectivist migrant group were motivated by and for family; similarly, Smith (2015) identified altruistic 'doing' as a prime motivator. Together, these findings help explain the overall drive towards altruism, community and integration through occupational preference found in this study. The majority of participants were alone, yet appeared 
to experience connection and belonging through contributing in an active, meaningful way. Some found faith bridged difference in the wider community but for many, Western expressions of community were simply alien, 'You go outside, you walk alone' (M6). These findings have implications for health and social care practice.

\section{Discussion}

Key themes arising from the study are discussed below in relation to the users of the drop in centre. These were: the need to experience community and being able to make an altruistic contribution, and having the opportunity to integrate into the community and engage in meaningful and productive occupations within it. When people migrate they leave their familiar home environment and live in environments that are different in terms of physical, economic, social and cultural attributes (Gupta and Sullivan, 2013). According to Whiteford (2005), having too much time, too little to do, a lack of resources and the effects of trauma all contribute to the state of occupational deprivation in the short term.

The findings from this study indicate that the ability to engage in meaningful occupations was positively associated with wellbeing and fitting in to the local community. Speaking to others and engaging in meaningful occupation helped people to engage in their transition to a new culture and new country and assisted in promoting health and wellbeing. Maintaining relationships with those from the same or similar backgrounds can lower the stress and impact of changing cultural contexts. 
Cultural dispositions towards collectivism were found to influence ways of coping with migration induced occupational disruption. Smith (2015) found that it was important for asylum seekers to be busy with a purpose, but they prized helping others above all else. This links to the theme of altruism. Altruism is often described as intrinsically motivated actions undertaken for the benefit of others (Draguns, 2013). Feelings of empathy with another and the notion of kinship were important (Batson, 2011). Collectivism was important for integration, and refugees and asylum seekers interviewed in this study sometimes found it difficult to align their experiences of collectivism with British culture. Altruistic activities were seen to increase levels of social interaction, life satisfaction and purpose. Smith's (2015) identification of altruism as a core motivation among this population coincides with a view held by the research team that there is a place for research which is proactively altruistic.

Several participants referred to the drop-in centre's role in supporting their integration into British culture and society. The drive to learn or improve English was strong, accompanied by an awareness that British culture was different and there was a need to consider the importance of understanding social conventions. Ikiugu and Rosso (2006) have argued that consistency of participating in previously liked occupations makes present occupations more meaningful. The women's preparation for the future, observable in learning English or making relationships and friendships, corresponds with these assumptions. 
Occupations such as volunteering to help other people to adjust to their cultural and personal needs when going through the asylum process was seen as a major part of the acculturation process and links with the collectivist culture. Sociocultural traditions influence how individuals organise their time, their routines and expectations of others and society as a whole (Larsen and Zemke, 2003). Occupational access and opportunities presented are a key way of ensuring the transition in to society and to find ways of doing, being and becoming in their new life (Wilcock, 1998., Bennett et al, 2012). Occupational justice is achieved when the socio-political environment enables people to engage in occupations of their choosing (Wilcock and Townsend, 2009). Contexts that disrupt or deprive a person from engaging in occupations that are meaningful are considered to be contributing to occupational injustice.

\section{Implications for future practice}

The findings indicate that women in particular are at risk of occupational alienation, due to the language barrier and the limitations of being a primary caregiver (Gupta and Sullivan, 2013); There is an identified need to support productive and leisure occupations for men, women and children. Scaffolding occupational adaptation and language acquisition through accessing service users occupational histories has proven effective (Werge-Olsen and Vik, 2012; Mirza, 2012). For women, applying this to relevant occupational activities such as food preparation and childcare could facilitate linguistic and social integration and counteract the common experience of loss of identity. Alongside this, Steindl et al (2008) observed that cooking and 
sharing meals is a meaningful occupation eroded among female refugees and their families by limited financial and personal resources.

Wright St-Clair (2012) highlights the importance of maintaining occupations which connect and reflect a person's past, present and future as a means of fostering wellbeing; It is recommended that practitioners adopt appropriate occupationfocussed group work, guided by the needs and preferences of service users (Liamputtong, 2008). This has the potential to foster emotional wellbeing, improve social relationships, scaffold language development and promote occupational adaptation.

In working with this client group, health and social care practitioners should be aware of the cultural motivations behind occupational preferences, respect the importance of interdependence and seek to incorporate a community element whenever possible. This should be done alongside work to support integration into the host community; while the legal and political climate creates barriers to this (Davies, 2009; De Mojeed, 2010), persistence and creativity may generate pockets of opportunity for cultural exchange in the host community, for example church communities or third sector volunteering (Burchett and Matheson, 2010).

There is a need to advocate for occupational justice at local and national level. Health and social care practitioners working with refugees and asylum seekers can raise awareness professionally and politically, bringing a unique voice to this debate. 


\section{Recommendations for Future Research}

It is recommended that a productive approach to further the initial study findings is to focus on how similar services can more effectively facilitate meaningful occupation with asylum seekers and refugees. The recruitment of an advisory group from among the service users would ethically assist this process. Given the findings of this study, the consideration of the needs of women and children should perhaps be prioritised. This could offer the cultural brokerage outlined by Eide and Allen (2005) and facilitate deeper exploration of the needs and wishes of women and children accessing similar services. Embedding these insights into subsequent research design and methodology will enable development of a project which is compassionate, ethical and of greatest benefit to both the client group and the research community.

\section{Limitations}

The limited opening hours of the drop-in centre (two hours, twice per week) restricted the amount of contact time between the research team and participants. Further interviews could have been conducted with additional time, however 18 participants supported the collection of valuable data. Replicating this study among other relevant support services could strengthen confirmability and yield further insights. Given that a phenomenological qualitative approach was used in this study, and the focus was on one specific service only, the findings lack transferability (Birks, 2014).

\section{Conclusion}


This study adds to the evidence base on occupational meaning and engagement among asylum seekers and refugees, highlighting the distinctive influence of collectivist culture on occupational preferences and the value of a drop-in centre service. In order to harness the potential of occupation within effective service provision in the transitional experiences of refugees and asylum seekers, the cultural framework influencing preferences needs to be recognised and respected. Support centres have meaning beyond what we might immediately perceive them to have, because they provide a space for culturally relevant community, but they are equally valued as a stepping stone to occupational adaptation and better integration. Displaced people need a place where their past and future selves can meet and walk side by side. Without knowledge of the differences between collectivist and individualist (Western) cultures, the occupational needs and motivations of this population group cannot be fully understood. This study provides an important cultural insight for professionals in all sectors who are working with asylum seekers and refugees, into the deeper value and meaning that support services for this specific user group can provide.

\section{Funding:}

This research received no specific grant from any funding agency in the public, commercial, or not-for-profit sectors.

\section{Disclosure Statement:}

No potential conflict of interest was reporting by the author(s). 


\section{Research Ethics:}

The study was approved by the York St John University School of Health Sciences research ethics committee. 


\section{References}

Adamson, J. and Donovan, J. (2002) Research in black and white. Qualitative Health Research, 12(6): pp.816-825

Baird, M, Bimali, M, Cott, A, Brimacombe, M, Ruhland-Petty, T and Daley, D. (2017) Methodological challenges in conducting research with refugee women. Issues in Mental Health Nursing, 38(4): pp.344-351

Barata, P C, Gucciardi, E, Ahmad, F and Stewart D E. (2006) Cross-cultural perspectives on research participation and informed consent. Social Science and Medicine. 62: pp.479-490

Batson, C. (2011) Altruism in humans. Oxford University Press: New York

Bennett, K M, Scornaiencki, J M, Brzozowski, J, Denis S and Magalhaes, L. (2012) Immigration and its impact on daily occupations: a scoping review. Occupational Therapy International. 19(4): pp.185-203

Birks, M. (2014) Quality in qualitative research, in. Mills, J and Birks, M. (eds) Qualitative methodology: a practical guide. Sage: London. pp.221-236

Bishop, R, Purcell, E. (2013) The value of an allotment group for refugees. British Journal of Occupational Therapy. 76(6): pp.264-269

British Institute of Human Rights. (2006) Your human rights: a guide for refugees and asylum seekers [Guide]. Available from: https://www.oneeastmidlands.org.uk/sites/default/files/library/bihr refugee gui de.pdf (Accessed 4th July 2018)

Burchett, N, Matheson, R. (2010). The need for belonging: the impact of restrictions on working on the well-being of an asylum seeker. Journal of Occupational Science. 17(2): pp.85-91

Crawford, E, Turpin, M. (2018) Intentional strengths interviewing in occupational justice research. Scandinavian Journal of Occupational Therapy. 25(1): pp.5260

Cresswell, J. (2014) Research design. 4th ed. Sage: Los Angeles

Dali, M. (2014). New website to facilitate migrants' integration: IOM Malta proposes the setting up of a one-stop-shop. Malta: MaltaToday. Available from: https://www.maltatoday.com.mt/news/national/40492/new_website_to_facilitat e_migrants_integration\#.W3pNxc4zblU (Accessed 4th October 2018)

Davies, R. (2009) Working with refugees and asylum seekers, in Pollard, N. (ed) $A$ political practice of occupational therapy. Churchill Livingstone/Elsevier: Edinburgh. pp.183-189 
De Mojeed, A. (2010) The effects of lack of occupation on the mental health of asylum seekers. Available from: http://www.oofras.com/rs/7/sites/177/user_uploads/File/Abiola's\%20Thesis\%2 02010.pdf (Accessed $4^{\text {th }}$ July 2018)

Douglas, A. (2010). Working with bereaved asylum-seekers and refugees. Bereavement Care. 29(3): pp.5-9

Draguns, J. (2013) Altruism in its personal, social and cultural contexts: an introduction, in Vakock, D (ed). Altruism in cross cultural perspectives. Springer: New York. pp.483-486

Durocher, E., Gibson, B E and Rappolot, S. (2014). Occupational justice: a conceptual review. Journal of Occupational Science. 21(4): pp.418-430

Eide, P. and Allen, C. (2005), Recruiting transcultural qualitative research participants: a conceptual model. International Journal of Qualitative Methods. 4(2): pp.1-10

Erden, O. (2017). Building bridges for refugee empowerment. Journal of International Migration and Integration. 18(1): pp.249-265

Finlay, L. (2006) Mapping methodology, in Ballinger, C and Finlay, L. (eds) Qualitative research for allied health professionals: challenging choices,. Whurr Publishing: Chichester. pp.9-29

Finlay, L. (2011) Phenomenology for psychotherapists: researching the lived world. Oxford: Wiley-Blackwell

Gallagher, M., Muldoon, O and Pettigrew, J. (2015). An integrative review of social and occupational factors influencing health and wellbeing. Frontiers in Psychology, 6: pp.1281

Green, J. and Thorogood, N. (2014) Qualitative methods for health research. 3rd ed. London: Sage

Gupta, J. and Sullivan, C. (2013). The central role of occupation in the doing, being and belonging of immigrant women. Journal of Occupational Science. 20(1): pp. $36-48$

Hammell, K. (2017) Critical reflections on occupational justice: towards a rightsbased approach to occupational opportunities. Canadian Journal of Occupational Therapy. 84(1): pp.47-57

Hasselkus, B. (2011). The meaning of everyday occupation. 2nd ed. 2011, Slack: Thorofare, $\mathrm{NJ}$ 
Heigl, F., Kinebanian, A and Josephsson, S. (2011) I think of my family, therefore I am: perceptions of daily occupations of some Albanians in Switzerland. Scandinavian Journal of Occupational Therapy. 18: pp.36-48

Howlett, F and Spring, H. (2018), 'The value and meaning of a community centre service for refugees and asylum seekers' paper presented at World Federation of Occupational Therapist Congress $22^{\text {nd }}$ May 2018, Cape Town International Convention Centre, South Africa. Available from: http://wfotcongress.org/downloads/abstracts/SE\%2013/The\%20Value $\% 20$ and \%20Meaning\%20of\%20a\%20Community\%20Centre\%20Service\%20for\%20R efugees $\% 20$ and $\% 20$ Asylum\%20Seekers.pdf (Accessed $12^{\text {th }}$ July 2018)

Huot, S., Kelly, E and Park, S J. (2016). Occupational experiences of forced migrants: a scoping review. Australian Occupational Therapy Journal. 63: pp.186-205

Ikiugu, M N and Rosso, H M. (2006). Understanding the occupational human being as a complex, dynamical, adaptive system. Occupational Therapy in Health Care. 19(4): pp.43-65

Iwama, M. (2006) The KAWA model: culturally relevant occupational therapy. Churchill Livingstone Elsevier: Edinburgh

Iwama, M. (2010). Cultural perspectives on occupation, in Christiansen, D H and Townsend, E A (eds). Introduction to occupation: the art and science of living,. Pearson: New Jersey. pp.35-55

Larsen, E. and Zemke, R. (2003). Shaping the temporal patterns: the social coordination of occupation. Journal of Occupational Science. 10(2): pp.80-89

Laverack, G. and Brown, K. (2003). Qualitative research in a cross-cultural context: Fijian experiences. Qualitative Health Research. 13(3): pp.333-342

Liamputtong, P. (2008). Researching refugees: methodological and ethical considerations, in Liamputtong, P (ed). Doing cross-cultural research: ethical and methodological perspectives. Springer: London

Liamputtong, P. (2010) Cross-cultural research and qualitative inquiry. Turkish Online Journal of Qualitative Inquiry. 1(1): pp.16

Lunden, E., (2012). Refugee resettlement through the lens of occupational therapy, University of Puget Sound

Mirza, M. (2012) Occupational upheaval during resettlement and migration: findings of global ethnography with refugees with disabilities. OTJR: Occupational, Participation and Health. 32(1): pp.S6-S14

Morville, A. (2014) Daily occupations among asylum seekers: experience, performance and participation. Medical Faculty, Lund University 
Oliveira, C R., Abranches, M., Healy. (2009) Handbook on how to implement a onestop-shop for immigrant integration. Available from: file:///C:/Users/h.spring/Downloads/30493516_File000003_722630193.pdf (Accessed 4th October 2018)

Pollard, N, Kronenberg, F and Sakellariou, D. (2009) Occupational apartheid: a political practice of occupational therapy, Churchill Livingstone Elsevier: Edinburgh

Pollard, N. and Sakellariou, D. (2017) Occupational therapies without borders: integrating justice and practice. 2nd ed. Elsevier: Edinburgh

Reeves, M., de Wildt, G., Murshali, H., Willims, P., Gill, P., Kralj, L and Rushby, M. (2006) Access to health care for people seeking asylum in the UK. British Journal of General Practice. 56(525): pp.306-308

Refugee Council. (2018) Quarterly asylum statistics. Available from: https://www.refugeecouncil.org.uk/assets/0004/3376/Asylum_Statistics_May_ 2018.pdf (Accessed 4th July 2018)

Richardson, E.Z.L., et al. (2017) "Taking care" in intercultural research: lessons from a Guatemalan family planning study. International Journal of Qualitative Methods. 16: pp.1-13

Ryen, A. (2008). Trust in cross-cultural research: the puzzle of epistemology, research ethics and context. Qualitative Social Work. 7: pp.448-465

Schweitzer, R. and Steel, Z. (2008). Researching refugees: methodological and ethical considerations, in Liamputtong, P. (ed).Doing cross-cultural research, Springer: London. pp.87-101

Sixsmith, J, Boneham, M and Goldring, J. (2003) Accessing the community: gaining insider perspectives from the outside. Qualitative Health Research. 13(4): pp.578-589.

Smith, C. (2015). An exploration of the meaning of occupation to people who seek asylum in the United Kingdom. British Journal of Occupational Therapy. 78(10): pp.614-621

Smith, J, Flowers, P and Larkin, M. (2009). Interpretative phenomenological analysis: theory, method and research. Sage: London

Steindl, C, Winding, K and Runge, U. (2008). Occupation and participation in everyday life: women's experiences of an Australian refugee camp. Journal of Occupational Science. 15(1): pp.36-42 
Suleman, A. and Whiteford, G. (2013). Understanding occupational transitions in forced migration: the importance of life skills in early refugee resettlement. Journal of Occupational Science. 20(2): pp.201-210

United Nations General Assembly, Convention relating to the status of refugees, in United Nations Treaty Series1951: United Nations. p. 137-220.

United Nations Refugee Agency. (2018). Figures at a glance. Available from: http://www.unhcr.org/uk/figures-at-a-glance.html (Accessed 4 July 2018)

Usher, K. and Jackson, D. (2014) Phenomenology. In Mills, M and Birks, M (eds) Qualitative methodology. Sage: London

Werge-Olsen, I. and Vik, K. (2012). Activity as a tool in language training for immigrants. Scandinavian Journal of Occupational Therapy. 19: pp.530-541

Whiteford, G. (2005) Understanding the occupational deprivation of refugees: a case study from Kosovo. Canadian Journal of Occupational Therapy. 77: pp.78-88.

Wilcock, A. (2006). An occupational perspective of health. Slack: Thorofare: New Jersey:

Wilcock, A. (1998). Reflections on doing, being and becoming. Canadian Journal of Occupational Therapy. 65(5): pp.248-256.

Wilcock, A. and Townsend, E A. (2009) Occupational justice, in Crepeau, E B, Cohn, E S and Schell, B A (eds) Willard and Spackman's Occupational Therapy. Lippincott, Williams and Wilkins: Philadelphia. pp.192-199.

Wilson, C. (2009) Illustrating occupational needs of refugees, in Pollard, N, Sakellariou D and Kronenberg, F. (eds). A political practice of occupational therapy, Churchill Livingstone Elsevier: Edinburgh. pp.191-196.

World Federation of Occupational Therapists. (2016) Definition 'occupation'. Available from: http://www.wfot.org/aboutus/aboutoccupationaltherapy/definitionofoccupationa Itherapy.aspx (Accessed 12th July 2018).

World Federation of Occupational Therapists. (2014) Position statement on human displacement (revised).

World Federation of Occupational Therapists (2006). Position statement on human rights.

Wright-St Clair, V. (2012). Being occupied with what matters in advanced age. Journal of Occupational Science. 19(1): pp.44-53. 
Table 1: Demographics of Participants

\begin{tabular}{|l|l|l|l|l|}
\hline Code & Origin & Religion & Status & Age \\
\hline F1 & Pakistan & Christian (R.C.) & Asylum Seeker & Not Given \\
\hline M2 & Afghanistan & Muslim & British Citizen & Not Given \\
\hline M3 & Iraq & Christian & British Citizen & $51-60$ \\
\hline F4 & Albania & Atheist & Refugee & $31-40$ \\
\hline M5 & Iran & Zorastrian & Refugee & $41-50$ \\
\hline M6 & Syria & Sunni Muslim & Refugee & $18-24$ \\
\hline M7 & Iran & Christian & Asylum Seeker & $31-40$ \\
\hline F8 & Nigeria & Christian (R.C.) & Asylum Seeker & $61-70$ \\
\hline M9 & Zimbabwean & Christian & Refugee & $61-70$ \\
\hline F10 & India & Atheist & Asylum Seeker & $31-40$ \\
\hline M11 & Afghanistan & Sikh & Asylum Seeker & $41-50$ \\
\hline M12 & Afghanistan & Sikh & Asylum Seeker & $31-40$ \\
\hline F13 & Iran & Christian & Asylum Seeker & $25-30$ \\
\hline F14 & Iranian & Muslim & Asylum Seeker & $18-24$ \\
\hline M15 & Sri Lanka & Atheist & Refugee & $41-50$ \\
\hline M16 & Iran & Christian & Refugee & $31-40$ \\
\hline M17 & Syria & Atheist & Asylum Seeker & $25-30$ \\
\hline F18 & Uganda & Christian & Asylum Seeker & $41-50$ \\
\hline
\end{tabular}


Table 2: Interview Schedule

1. How did you first hear about the drop-in?

2. How long have you been coming to the drop-in?

3. Why do you come to the drop-in?

4. What is it like to belong to the drop-in community?

5. What do you enjoy about the drop-in?

6. Is there anything you do not enjoy about the drop-in?

7. What could we do to make the drop-in better?

8. Would you recommend the drop-in to a friend?

9. Is there anything else you would like to say?

10. Would you like to receive a copy of a summary of this interview?

Probing questions for clarification included: 'Can you say why?' / 'Can you tell me more about that?' Questions could be rephrased for comprehension if necessary. 